Research Article

\title{
Dietary Practice and Associated Factors among Pregnant Women in Misha Woreda, South Ethiopia: A Community-Based Cross-Sectional Study
}

\author{
Lonsako Abute $\mathbb{D}^{D}$, Abera Beyamo $(\mathbb{D}$, Belay Erchafo, Tegegn Tadesse, Dawit Sulamo $\mathbb{D}$, \\ and Tagesse sadoro
}

Public Health Department, College of Medicine and Health Sciences, Wachemo University, Hossana, Ethiopia

Correspondence should be addressed to Lonsako Abute; bt.lnsk@gmail.com

Received 25 June 2020; Revised 2 September 2020; Accepted 7 September 2020; Published 25 September 2020

Academic Editor: Luigi Schiavo

Copyright $\odot 2020$ Lonsako Abute et al. This is an open access article distributed under the Creative Commons Attribution License, which permits unrestricted use, distribution, and reproduction in any medium, provided the original work is properly cited.

Background. Proper food and good nutrition are essential for survival, physical growth, mental development, performance and productivity, and health and well-being. Pregnancy is a critical phase in a woman's life. The aim of this study is to assess the dietary practice and associated factors among pregnant women in Misha woreda, south Ethiopia. Methods. A crosssectional study was conducted in Misha woreda, South Ethiopia, on pregnant women. Data were collected by using a structured interviewer-administered questionnaire. The data were entered in EpiData V-3.1 and analyzed using SPSS version 21. Binary logistic regression analysis was also employed to examine the association between dependent and independent variables. A $P$ value of $<0.05$ was considered as the cutoff point to declare statistical significance. Result. Out of 618 pregnant women, almost all of them 618 interviewed with the response rate of $100 \%$. The mean age of pregnant women was 27.31 years $( \pm 5.622)$. From total study participants, $54.1 \%$ of the respondents were followers of protestant religion and $80.2 \%$ of husband occupation were farmers and $78.7 \%$ pregnant women occupation were house wives. From the total participants, $43.6 \%$ had illness on the current pregnancy. Almost two third $66.2 \%$ of the pregnant women travel $\geq 1 \mathrm{hr}$ to reach HF. Majority of the participants (62\%) had moderate knowledge about dietary practice in pregnancy, and $29.5 \%$ practiced good dietary practice. Educational status $(\mathrm{AOR}=4.07[2.13,9.18])$, occupation $(\mathrm{AOR}=5.32[1.08,13.95])$, dietary knowledge $(\mathrm{AOR}=7.2[3.9$, $17.09])$, and food craving $(\mathrm{AOR}=2.07[1.41,5.5])$ were variables having a significant association with dietary practice. Conclusion. The prevalence of good dietary practice among pregnant women in Misha district was low when compared to other studies. According to the study result, educational status, occupation, dietary knowledge, and food craving were factors that affect dietary practice.

\section{Background}

Both developed and developing countries have the problem of nutritional problem; it may be under or over nutrition, but pregnent mothers are more vulnerable for it [1]. Nutritional status of pregnant mother determine health and well-being of the mother and her child. This mother requires more energy and nutrients to meet the need of the growing fetus and maternal tissues [2]. Therefore, practicing dietary balance ensures sufficient energy intake for growth of the fetus [3]. In Ethiopia, nutritional disorders are among the main causes of maternal morbidity and mortality. The major nutritional disorders are proteinenergy malnutrition and micronutrient deficiencies in this country [4]. Twenty-two percent of women are undernourished with a body mass index (BMI) less than 18.5 [5].

Pregnant woman are in a particular risk for nutritional deficiencies if they were adolescent, underweight, smokers, alcohol/drugs users and have chronic nutritional problems or chronic illnesses [6]. Poor nutrition of women with lack of care contributes to death in pregnant mother [7]. The mother's death also compromises health and survival of the infant and children. The effects of maternal under nutrition peak during pregnancy and within the first two years of 
child. Furthermore, effects on brain development, intelligence, educability, and productivity are mainly irreversible [8].

The adequate maternal nutrition is one of the best ways to ensure maternal and fetal well-being. Therefore, good dietary practice of pregnant mother reduces the risk of chronic diseases. The consistent evidence about the pregnant mothers' dietary practice is lacking in the study area. So, this study aimed to assess the dietary practice and associated factors among pregnant women in Misha woreda, Southern Ethiopia.

\section{Methods}

2.1. Study Design Period and Area. A community-based cross-sectional study was conducted in pregnant women in Misha woreda, from April 1 to May 30, 2019. The woreda contains 23 kebeles ( 2 urban and 21 rural kebeles) with a total population of 103,000 with $49.47 \%$ of male and $50.53 \%$ of female. In the woreda, there are 3,564 expected numbers of pregnant women. As to health infrastructures, there are three functional health centers.

2.2. Study Population and Sampling. All pregnant women who live in Misha woreda were considered as the source population, and sampled pregnant women in the randomly selected kebeles were taken as the study population.

Sample size was calculated by using the single population proportion formula based on the following parameters: $95 \%$ confidence level (1.96), margin of error (0.05) and 27\%, the prevalence of good dietary practice as during pregnancy from Gondar (13) and design effect 2, and 10\% none response. The calculated sample size was 618 pregnant mothers in Misha Woreda, Hadiya Zone, Southern Ethiopia. To access study participants, first of all, the kebeles were stratified into urban and rural. There are 21 rural and 2 urban kebeles in the woreda. So that, 1 urban and 7 rural with a total of 8 kebeles were taken randomly. After doing preliminary assessment to identify those pregnant mothers in the selected kebeles, sample seize was distributed proportional to population size for each kebeles. Finally, the systematic sampling technique was used to select 618 pregnant women by preparing the sampling frame.

2.3. Data Collection Instrument and Data Collectors. A quantitative method of data collection was employed for assessment of dietary practice among pregnant mothers in Misha district, Hadiya Zone, Southern Ethiopia, by using a face-to-face interviewer-administered questionnaire. The tool has six sections such as sociodemographic characteristics of the respondents ( 9 questions), obstetric and related characteristics (6 questions), health services and householdrelated characteristics (5 questions), dietary knowledge of pregnant mothers (10 questions), meal pattern of pregnant mothers (11questions), and dietary practice of pregnant mothers (13 questions). Dietary practice was determined using questions related to dietary practices of pregnant mothers. The questionnaire of practice on food and nutrition was used in this study to measure dietary practices. Scores of dietary practices were obtained by summation of each group of questions. Each question was given one mark if the answers are correct, favorable, or healthy for dietary practice. Zero score was given if the responses are wrong, unfavorable, or unhealthy for dietary practice questions. The score of the respondents was taken, and respondents were classified as having good or poor dietary practices by taking their responses $\geq 75 \%$ and below $75 \%$, respectively.

2.4. Data Quality Control. For administering the structured questionnaire, four BSc and eight diploma nurse professionals were employed a supervisor and data collector, respectively, in the woreda. The questionnaire was prepared in English and, then, translated into the local language and translated back into English language by another language expert to check consistency. Two days of training was given for data collectors and supervisors on the objective, relevance of the study, confidentiality of information, respondent's right, time of data collection from the kebeles, and submission on due time. The pretest was conducted on $5 \%$ of the actual sample size in Gibe woreda pregnant women. The collected data were checked for completeness and consistency in daily basis.

2.5. Data Processing and Analysis. Data were entered into EpiData version 3.1and exported to SPSS 20.0 statistical software to edit, clean for inconsistencies and missing values, and finally, to analyze. Descriptive analysis was carried out for each of the variables to check frequency, distribution, and missing value. Bivariate logistic regression analysis was employed to check crude association between dietary practice and independent variables. Variables with a $p$ value $<0.25$ on bivariate logistic regression analysis were entered into multivariable logistic regression to identify the factors that affect dietary practice. Odds ratio and the corresponding 95\% confidence intervals were used to quantify the degrees of association between the independent variable and the outcome variable. Results with a $p$ value $<0.05$ were considered as being statistically significant, and the rest was refuted. Multicollinearity among independently associated variables was checked by a multicollinearity diagnostic test VIF in linear regression, and none was collinear.

2.5.1. Dietary Practices. Seven dietary practice questions were designed to assess practices of mothers on nutrition during pregnancy. The result was obtained by summation of each group of questions. Each question was given one mark if the answer is correct, favorable, or healthy for dietary practice. Zero score was given if the responses are wrong, unfavorable, or unhealthy for dietary practice questions. The score of the respondents was taken, and respondents were classified as good dietary practice if the score $>75 \%$ and poor dietary practices if below $75 \%[9,10]$.

2.5.2. Knowledge of Dietary Practice. Eight dietary knowledge question was asked, and each item was given a score of 
1 (correct) or 0 (incorrect), and the sums were used as the knowledge scores. Finally, it was classified as good knowledgeable if the score was $>70 \%$ and poor knowledgeable if below $70 \%[9,10]$.

2.5.3. Meal Pattern. Avoidance or skipping from the habitual meal relating with the pregnancy outcome.

\section{Results}

3.1. Sociodemographic Characteristics. Out of 618 pregnant women, almost all of them were interviewed for this study and yielding their response rate of $100 \%$. The mean age of pregnant women was 27.31 years $( \pm 5.622)$. From total study participants, 334 (54.1\%) of the respondents were followers of protestant, and 225 (36.4\%) were orthodox. Among the study subjects, the occupation of husbands of 495 (80.2) was farming, and $486(78.7 \%)$ pregnant women were house wives. Majority of the respondents' (231 (37.3)) educational status was can read and write. Two hundred and sixty (42) of the respondents have the family size of 3-4. Regarding average monthly income of the family, more than half (184 (54.4\%)) got less than 2000 birr per month, and 336 (54.4\%) of them got $<2000$ birr per month (Table 1).

3.2. Obstetric and Health Service-Related Factors of the Pregnant Women. From a total of 618 participants, 284 (46\%) pregnant mothers were in the second trimester of the pregnancy and $429(69.3 \%)$ of them had 3-5 pregnancies before the current pregnancy and 309 (50\%) had 2-5 years gap duration between previous and current pregnancy. From the total participants, 269 (43.6\%) had illness on the current pregnancy, and headache and blurred vision were the leading illnesses (186 (69\%)). Almost two-third (409 $(66.2 \%)$ ) of the pregnant women travel $\geq 1 \mathrm{hr}$ to reach HF. Only $28.2 \%$ of the participants got support from their husband during their pregnancy nutritionally, and the majority (112 (64.6\%)) were supported by reminding to consume foods or supplements (Table 2).

3.3. Dietary Knowledge of the Pregnant Women. It is revealed that the majority of the participants $(383(62.0 \%))$ had moderate knowledge about dietary practice in pregnancy (Table 3).

3.4. Meal Pattern of Pregnant Mothers. From a total of 618 respondents, $36.9 \%$ pregnant women consume additional meal and $83.3 \%$ of those have one extra meal within a day. From those who did not consume additional meal, poor economy (39.6\%) and considered as adequate (31.5\%) were the main reasons. One hundred and twenty-nine (20.9\%) of the respondents have the history of skipping meal, and personal dislike (36.8\%) and fear of obesity (35.1\%) were the major ones. From the total participants, $33 \%$ practiced food avoiding, and majority (52.1\%) of them avoid due to cultural reasons such as it will make baby big and labor difficulty (33.6\%), will be plastered on the fetal head (37.9\%), and evil eye (28.5\%). A total of 256 (41.2\%) of the participants have food desire strongly (craving), and food odor (47.4\%) accounts the major reason to crave food items. Almost onethird of them did not get the craved food, and the main reason for not getting the craved food was nonavailablility (71.3\%) (Table 4).

3.5. Dietary Practices of Pregnant Mothers during Pregnancy. From the total of 618 participants, 181 (29.5\%) practiced good dietary practice while $437(70.5 \%)$ had poor dietary practice (Figure 1).

To identify factors associated with dietary practices, both binary and multivariate logistic regression models were used. Accordingly, factors that were associated with dietary practices of a pregnant mother under binary logistic regression were age of pregnant women, educational status of pregnant women, monthly income, occupation of pregnant women, husband support, gap between pregnancy, dietary knowledge, additional meal, meal skipping, and food craving which were significantly associated with dietary practice of pregnant women at a $p$ value 0.25 (Table 5).

3.6. Factors That Affect Dietary Practice among Pregnant Mothers. The variables that showed a significant association with dietary practice during pregnancy were adjusted for their confounders using the multivariate logistic regression educational status, occupation, monthly income, dietary knowledge, additional meal, and food craving that became independent predictors for dietary practices. Those literate pregnant women were four times $(\mathrm{AOR}=4.07[2.13,9.18])$ more likely good dietary practice than illiterate. Those who had an estimated family average monthly income of $\geq 4000$ birr were 5 times $(\mathrm{AOR}=5.32[1.08,13.95])$ more likely to have good dietary practice than those who had an estimated family monthly income less than 2000.00 birr (AOR $=5.32$ $[1.08,13.95])$. Pregnant mothers of government employers were seven times (AOR 7.2 [3.9, 17.09]) more likely to have good dietary practice than house wives. Also, those pregnant women with high dietary knowledge were eight times $(\mathrm{AOR}=8.53[2.19,21.05])$ more likely to have good dietary practice than mothers of poor dietary knowledge. Pregnant mothers who take additional meal were four times $(\mathrm{AOR}=4.7[1.6,10.3])$ more likely to have good dietary practice than mothers with no additional meal, and those mothers with no food craving were two times $(\mathrm{AOR}=2.07$ $[1.41,5.5])$ more likely to have good dietary practice than mothers with food craving (Table 6).

\section{Discussion}

In this study, only $29.5 \%$ of the pregnant mothers were found to have good dietary practice during their pregnancy. The finding of this study is higher than that of a study done in the West Gojjam Zone (19.9\%) [9]. The study finding is lower than the study findings of Bahir Dar town (39.3\%) [11], Dessei town (45.2) [12], Jille Tumuga district (31.4\%) [13], and Gonder town (40.10\%) [10]. The reason for this discrepancy might be due to differences in 
TABLE 1: Sociodemographic characteristics of pregnant mothers in Misha woreda, 2019.

\begin{tabular}{|c|c|c|c|}
\hline Explanatory variables & Category & Frequency & Percent \\
\hline \multirow{3}{*}{ Age } & $18-26$ & 296 & 47.9 \\
\hline & $27-35$ & 258 & 41.7 \\
\hline & $\geq 36$ & 64 & 10.4 \\
\hline \multirow{4}{*}{ Religion } & Protestant & 334 & 54.1 \\
\hline & Orthodox & 225 & 36.4 \\
\hline & Muslim & 46 & 7.4 \\
\hline & Catholic & 13 & 2.1 \\
\hline \multirow{3}{*}{ Marital status } & Married & 583 & 94.4 \\
\hline & Widowed & 25 & 4.0 \\
\hline & Divorced & 10 & 1.6 \\
\hline \multirow{4}{*}{ Husband educational status } & No formal education & 143 & 23.1 \\
\hline & Can read and write & 230 & 37.2 \\
\hline & Primary & 148 & 23.9 \\
\hline & Secondary and above & 97 & 15.7 \\
\hline \multirow{4}{*}{ Husband occupation } & Employed & 42 & 6.8 \\
\hline & Merchant & 48 & 7.7 \\
\hline & Daily labourer & 33 & 5.3 \\
\hline & Farmer & 495 & 80.2 \\
\hline \multirow{4}{*}{ Maternal education } & No formal education & 184 & 29.8 \\
\hline & Can read and write & 231 & 37.3 \\
\hline & Primary & 177 & 28.7 \\
\hline & Secondary and above & 26 & 4.2 \\
\hline \multirow{4}{*}{ Maternal occupation } & House wife & 486 & 78.7 \\
\hline & Government employed & 23 & 3.8 \\
\hline & Merchant & 48 & 7.7 \\
\hline & Daily laborer & 61 & 9.8 \\
\hline \multirow{3}{*}{ Family size of respondents } & $\leq 2$ & 137 & 22.2 \\
\hline & $3-4$ & 260 & 42.0 \\
\hline & $\geq 5$ & 221 & 35.8 \\
\hline \multirow{3}{*}{ Average monthly income (Ethiopian birr) } & $<2000.00$ & 336 & 54.4 \\
\hline & $2000.00-4000.00$ & 227 & 36.7 \\
\hline & $>4000.00$ & 55 & 8.9 \\
\hline
\end{tabular}

TABLE 2: Obstetric and health service-related factors of the pregnant women in Misha woreda, 2019.

\begin{tabular}{|c|c|c|c|}
\hline Explanatory variable & Category & Frequency & Percent \\
\hline \multirow{3}{*}{ Trimester of the pregnancy } & First & 93 & 15.0 \\
\hline & Second & 284 & 46.0 \\
\hline & Third & 241 & 39.0 \\
\hline \multirow{3}{*}{ Number of pregnancies before the current pregnancy } & $\leq 2$ & 165 & 26.8 \\
\hline & $3-5$ & 429 & 69.3 \\
\hline & $5+$ & 24 & 3.9 \\
\hline \multirow{3}{*}{ Gap duration between the past and current pregnancy } & $\leq 2$ years & 263 & 42.5 \\
\hline & $3-5$ years & 309 & 50.0 \\
\hline & $5+$ years & 46 & 7.5 \\
\hline \multirow{2}{*}{ History of illness on current pregnancy } & Yes & 269 & 43.6 \\
\hline & No & 349 & 56.4 \\
\hline \multirow{3}{*}{ Kind of illness } & Headache and blurred vision & 186 & 69.0 \\
\hline & Lower abdominal pain & 35 & 13.0 \\
\hline & Vomiting and epigastric pain & 86 & 32.0 \\
\hline \multirow{3}{*}{ Time of initiation of ANC visits } & $<3$ months of pregnancy & 130 & 21.0 \\
\hline & 3-6 months & 414 & 67.0 \\
\hline & $>6$ months & 74 & 12.0 \\
\hline \multirow[b]{2}{*}{ Number of ANC visits } & $\leq 4$ visits & 569 & 92.0 \\
\hline & $>4$ visits & 49 & 8.0 \\
\hline \multirow{2}{*}{ Time that takes to reach HF } & $<1 \mathrm{hr}$ & 209 & 33.8 \\
\hline & $\geq 1 \mathrm{hr}$ & 409 & 66.2 \\
\hline \multirow{2}{*}{ Husband support } & Yes & 174 & 28.2 \\
\hline & No & 444 & 71.8 \\
\hline \multirow{2}{*}{ The way he supports you } & By purchasing diverse foods/supplements & 62 & 35.4 \\
\hline & By reminding me to consume these foods or supplements. & 112 & 64.6 \\
\hline
\end{tabular}


TABLE 3: Dietary knowledge of the pregnant women in Misha woreda, 2019.

\begin{tabular}{lcc}
\hline Knowledge category & Frequency & Percent \\
\hline High & 173 & $28.0 \%$ \\
Moderate & 383 & $62.0 \%$ \\
Low & 62 & $10.0 \%$ \\
\hline
\end{tabular}

TABLE 4: Meal pattern of pregnant mothers in Misha woreda, 2019.

\begin{tabular}{|c|c|c|c|}
\hline Variables & Category & Frequency & Percent \\
\hline \multirow{2}{*}{ Additional meal consumed } & Yes & 228 & 36.9 \\
\hline & No & 390 & 63.1 \\
\hline \multirow{2}{*}{ Number of extra meals within a day } & Once & 190 & 83.3 \\
\hline & Twice & 38 & 16.7 \\
\hline \multirow{3}{*}{ Reason of not having an additional meal } & Lack of information & 113 & 28.9 \\
\hline & Poor economy & 154 & 39.6 \\
\hline & Considered as adequate & 123 & 31.5 \\
\hline \multirow{2}{*}{ Skipping meal } & Yes & 129 & 20.9 \\
\hline & No & 489 & 79.1 \\
\hline \multirow{3}{*}{ Reason of meal skipping } & Personal dislike & 47 & 36.8 \\
\hline & Fear of obesity & 45 & 35.1 \\
\hline & Poor economy & 37 & 28.1 \\
\hline \multirow{2}{*}{ Fasting habits during pregnancy } & Yes & 48 & 7.8 \\
\hline & No & 570 & 92.2 \\
\hline \multirow{2}{*}{ Food avoided during pregnancy } & Yes & 204 & 33.0 \\
\hline & No & 414 & 67.0 \\
\hline \multirow{2}{*}{ Reason of food avoidance } & Personal dislike/aversion & 98 & 47.9 \\
\hline & Not allowed to pregnant women/cultural taboo & 106 & 52.1 \\
\hline \multirow{3}{*}{ Reason of cultural beliefs/taboo } & Will make baby big and labour difficulty & 36 & 33.6 \\
\hline & Will be plastered on the fetal head & 40 & 37.9 \\
\hline & Evil eye & 30 & 28.5 \\
\hline \multirow{2}{*}{ Any food desired strongly (craving) } & Yes & 256 & 41.2 \\
\hline & No & 363 & 58.8 \\
\hline \multirow{3}{*}{ Reason to crave for these food items } & Colour of food & 52 & 20.4 \\
\hline & Food odor & 121 & 47.4 \\
\hline & I do not know the reason & 83 & 32.2 \\
\hline \multirow{2}{*}{ Did you get the food you crave } & Yes & 170 & 66.4 \\
\hline & No & 86 & 33.6 \\
\hline \multirow{2}{*}{ The reason of not getting craved food } & Not affordable & 25 & 28.7 \\
\hline & Not available & 61 & 71.3 \\
\hline
\end{tabular}

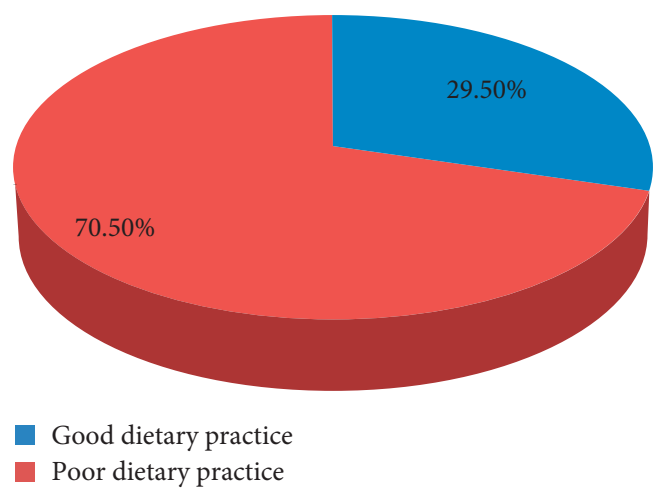

FIGURE 1: Dietary practices of pregnant mothers during pregnancy in Misha woreda, 2019. 
TABLE 5: Binary logistic regression with its COR for variables predicting dietary practice among pregnant mothers, Misha woreda, 2020.

\begin{tabular}{|c|c|c|c|c|}
\hline \multirow{2}{*}{ Variables } & \multicolumn{2}{|c|}{ Dietary practice } & \multirow{2}{*}{ COR $[95 \% \mathrm{CI}]$} & \multirow{2}{*}{$p$ value } \\
\hline & Good & Poor & & \\
\hline \multicolumn{5}{|l|}{ Age } \\
\hline $18-26$ & $56(9.10 \%)$ & $240(38.83 \%)$ & $0.34[1.01,13.05]$ & 0.03 \\
\hline $27-35$ & 97 (15.70\%) & $161(26.05 \%)$ & $0.95[0.23,6.02]$ & 0.23 \\
\hline$\geq 36$ & $28(4.53 \%)$ & $44(7.12 \%)$ & 1 & \\
\hline \multicolumn{5}{|l|}{ Marital status } \\
\hline Married & $150(24.27 \%)$ & $413(66.83 \%)$ & $0.21[0.05,2.03]$ & 0.62 \\
\hline Divorced & $9(1.46 \%)$ & $11(1.78 \%)$ & $0.48[0.23,6.72]$ & 0.81 \\
\hline Widowed & $22(3.56 \%)$ & $13(2.10 \%)$ & 1 & \\
\hline \multicolumn{5}{|l|}{ Occupation } \\
\hline Merchant & $20(3.24 \%)$ & $28(4.53 \%)$ & $0.77[0.20,2.97]$ & 0.12 \\
\hline Daily labourer & $31(5.02 \%)$ & $30(4.85 \%)$ & $0.46[0.17,1.21]$ & 0.21 \\
\hline Government employee & 37 (5.99\%) & $16(2.59 \%)$ & $0.40[0.15,1.02]$ & 0.002 \\
\hline House wife & $93(15.05 \%)$ & $363(58.74 \%)$ & 1 & \\
\hline \multicolumn{5}{|l|}{ Education } \\
\hline Read and write & $41(6.63 \%)$ & $110(17.80 \%)$ & $1.26[0.18,2.39]$ & 0.22 \\
\hline $1-8$ & $42(6.80 \%)$ & $135(21.84 \%)$ & $1.05[0.24,4.39]$ & 0.12 \\
\hline Secondary and above & $56(9.065 \%)$ & $50(8.10 \%)$ & $3.40[0.52,8.91]$ & 0.04 \\
\hline Cannot read and write & $42(6.80 \%)$ & $142(22.98 \%)$ & 1 & \\
\hline \multicolumn{5}{|l|}{ Income } \\
\hline$<2000$ & $77(12.46 \%)$ & $259(41.91 \%)$ & $0.20[0.28,1.74]$ & 0.15 \\
\hline $2000-4000$ & $69(11.17 \%)$ & $158(25.57 \%)$ & $0.25[0.20,1.18]$ & 0.023 \\
\hline$>4000$ & $35(5.66 \%)$ & $20(3.24 \%)$ & 1 & \\
\hline \multicolumn{5}{|l|}{ Husband support } \\
\hline Yes & $76(12.23 \%)$ & $98(15.86 \%)$ & $2.60[0.46,8.12]$ & 0.14 \\
\hline No & $105(16.99 \%)$ & $339(54.85 \%)$ & 1 & \\
\hline \multicolumn{5}{|l|}{ Gap between pregnancy } \\
\hline$\leq 2 \mathrm{yr}$ & $81(13.11 \%)$ & $162(26.21 \%)$ & $1.52[1.41,5.02]$ & 0.47 \\
\hline $3-5 \mathrm{yr}$ & $59(9.55 \%)$ & $150(24.27 \%)$ & $1.20[1.28,4.91]$ & 0.11 \\
\hline$>5 \mathrm{yr}$ & $41(6.63 \%)$ & $125(20.23 \%)$ & 1 & \\
\hline \multicolumn{5}{|l|}{ Dietary knowledge } \\
\hline Good & $128(20.71 \%)$ & $230(37.22 \%)$ & $2.17[2.28,13.02]$ & 0.003 \\
\hline Poor & $53(8.58 \%)$ & $207(33.50 \%)$ & 1 & \\
\hline \multicolumn{5}{|l|}{ Additional meal } \\
\hline Yes & $107(17.31 \%)$ & $121(19.58 \%)$ & $3.80[1.50,5.86]$ & 0.04 \\
\hline No & $74(11.97 \%)$ & $316(50.97 \%)$ & 1 & \\
\hline \multicolumn{5}{|l|}{ Meal skipping } \\
\hline Yes & $31(5.02 \%)$ & $98(15.86 \%)$ & $0.71[1.08,11.67]$ & 0.13 \\
\hline No & $150(24.27 \%)$ & $339(54.85 \%)$ & 1 & \\
\hline \multicolumn{5}{|l|}{ Food craving } \\
\hline Yes & $91(14.72 \%)$ & $113(18.28 \%)$ & $2.90[0.52,8.91]$ & 0.09 \\
\hline No & $90(14.56 \%)$ & $324(52.43 \%)$ & 1 & \\
\hline \multicolumn{5}{|l|}{ Time of initiation ANC visit } \\
\hline$<3$ months of pregnancy & $69(11.17 \%)$ & $165(26.70 \%)$ & $0.73[0.36,5.85]$ & 0.87 \\
\hline $3-6$ months of pregnancy & $85(13.75 \%)$ & $225(36.41 \%)$ & $0.66[0.53,1.89]$ & 0.98 \\
\hline$>6$ months of pregnancy & $27(4.37 \%)$ & $47(7.61 \%)$ & 1 & \\
\hline \multicolumn{5}{|c|}{ Time that takes to reach health facility } \\
\hline$<1$ hour & $99(16.02 \%)$ & $110(17.80 \%)$ & $3.60[1.28,4.91]$ & 0.65 \\
\hline$\geq 1$ hour & $82(13.27 \%)$ & $327(52.91 \%)$ & 1 & \\
\hline \multicolumn{5}{|l|}{ Additional meal } \\
\hline Yes & $112(18.12 \%)$ & $116(18.77 \%)$ & $4.50[0.48,1.94]$ & 0.86 \\
\hline No & $69(11.17 \%)$ & $321(51.94 \%)$ & 1 & \\
\hline
\end{tabular}

sociodemographic characteristics. Most of the studies have been conducted at towns which have different living conditions.

This study showed the educational status as significant factor with dietary practice. Literate mothers have good dietary practice when compared to illiterates. This finding was supported with another study conducted at America [14] and Gondar town [10]. The reason might be the demographic factors and accessibility difference among the study populations. 
TABLE 6: Variables predicting dietary practice among pregnant mothers in logistic regression.

\begin{tabular}{|c|c|c|c|c|}
\hline \multirow{2}{*}{ Variables } & \multicolumn{2}{|c|}{ Dietary practice } & \multirow{2}{*}{ COR $[95 \% \mathrm{CI}]$} & \multirow{2}{*}{ AOR (95\% CI) } \\
\hline & Good & Poor & & \\
\hline \multicolumn{5}{|l|}{ Age } \\
\hline $18-26$ & $80(12.94 \%)$ & $211(34.14 \%)$ & $0.35[1.0,33.5]$ & $2.07[0.19,7.9)]$ \\
\hline$\geq 27$ & $170(27.51 \%)$ & $157(25.40 \%)$ & 1 & \\
\hline \multicolumn{5}{|l|}{ Education } \\
\hline Literate & $166(26.86 \%)$ & $160(25.89 \%)$ & $7.22[1.02,7.6]$ & $4.07[2.13,9.18]^{*}$ \\
\hline Illiterate & $31(5.02 \%)$ & $261(42.23 \%)$ & 1 & \\
\hline \multicolumn{5}{|l|}{ Monthly income } \\
\hline$\geq 4000$ & $160(25.89 \%)$ & $176(28.48 \%)$ & $0.25[1.4,6.3]$ & $5.32[0.08,13.95]$ \\
\hline$<4000$ & $221(35.76 \%)$ & $61(9.87 \%)$ & 1 & \\
\hline \multicolumn{5}{|l|}{ Occupation } \\
\hline Government employed & $97(15.70 \%)$ & $15(2.43 \%)$ & $14.82[2.6,8.9]$ & $7.2[3.9,17.09]^{* *}$ \\
\hline Housewife & $154(24.92 \%)$ & $353(57.12 \%)$ & 1 & \\
\hline \multicolumn{5}{|l|}{ Husband support } \\
\hline Yes & $76(12.23 \%)$ & $98(15.86 \%)$ & $5.61[0.46,8.2]$ & $4.03[2.01,8.65]$ \\
\hline No & $105(16.99 \%)$ & $339(54.85 \%)$ & 1 & \\
\hline \multicolumn{5}{|l|}{ Gap between pregnancy } \\
\hline$\leq 2$ years & $74(11.97 \%)$ & $189(30.58 \%)$ & $0.74[1.4,5.02]$ & $3.03[0.61,7.15]$ \\
\hline$>2$ years & $107(17.31 \%)$ & $248(40.13 \%)$ & 1 & \\
\hline \multicolumn{5}{|l|}{ Dietary knowledge } \\
\hline High & $128(20.71 \%)$ & $230(37.22 \%)$ & $6.90[2.8,13.2]$ & $8.5[2.19,21.05]^{* *}$ \\
\hline Low & $53(8.58 \%)$ & $207(33.50 \%)$ & 1 & \\
\hline \multicolumn{5}{|l|}{ Additional meal } \\
\hline Yes & $112(18.12 \%)$ & $116(18.77 \%)$ & $6.71[4.2,14.2]$ & $5.03[0.64,11.3]^{*}$ \\
\hline No & $69(11.17 \%)$ & $321(51.94 \%)$ & 1 & \\
\hline \multicolumn{5}{|l|}{ Skipping meal } \\
\hline Yes & $31(5.02 \%)$ & $98(15.86 \%)$ & $1.20[1.2,4.9]$ & $2.3[0.92,6.84]$ \\
\hline No & $150(24.27 \%)$ & $339(54.85 \%)$ & 1 & \\
\hline \multicolumn{5}{|l|}{ Food craving } \\
\hline Yes & $91(14.72 \%)$ & $113(18.28 \%)$ & 1 & \\
\hline No & $90(14.56 \%)$ & $324(52.43 \%)$ & $1.25[0.4,6.2]$ & $2.07[1.41,5.5]^{*}$ \\
\hline
\end{tabular}

$* *=p$ value $<0.001, *=p$ value $<0.05$.

This study indicates that the mother's occupation was a significant factor of dietary practice of a pregnant mother. Mothers engaged in government work were seven times more likely to practice good dietary practice than house wives $(\mathrm{AOR}=7.2,3.9,17.09)$. This finding is supported by a previous study conducted in Kenya [15] and in Addis Ababa [16]. The reason might be that those mothers engaged in government work may be more accessible to get more information about the diet during pregnancy and they may adhere to practice more than house wives.

Moreover, in this study, women's dietary knowledge had shown a positive relationship with dietary practice of mothers during pregnancy ( $\mathrm{AOR}=8.5,2.19-21.05)$. This finding is supported by the study conducted in West Gojjam [9], Kenya [15], and Addis Ababa [16]. The reason behind the similarity might be due to the fact that when the women is exposed to dietary information, they may be informed of the consequences of undernutrition on their children, as well as on themselves, and they will more enforced to practice adequate diet.

Presence of food craving has a negative association with good dietary practice. Those mothers with no food craving were two times more likely to practice good dietary practice than those with food craving $(\mathrm{AOR}=2.07$, $1.41-5.5)$

\section{Conclusions}

The prevalence of good dietary practice among pregnant women in Misha district was low when compared to other studies. According to the study result, being literate, being government employee, and having good dietary knowledge were facilitators of good dietary practice whereas food craving was an inhibitor of good dietary practice.

5.1. Recommendation. Based on the findings, the following recommendations were forwarded for identified gaps: Misha district health office, health extension worker, and health workers due attention to maximize the prevalence of good dietary practice by awareness creation of pregnant mothers. The Department of Public Health, Wachemo University, College of Medicine and Health Science, should also takes responsibility for further assessments on dietary practice to identify additional factors affecting dietary practices of pregnant mothers. The Wachemo University Research and 
Community Service Directorate should prepare interventional training for pregnant mothers towards dietary practice on identified gaps.

\section{Abbreviation}

AOR: Adjusted odds ratio

BMI: Body mass index

COR: Crude odds ratio

SPSS: Statistical package for social science.

\section{Data Availability}

The data used to support the findings of this study are available from the corresponding author upon request.

\section{Ethical Approval}

Ethical clearance was obtained from the ethical review committee of Wachemo University, College of Health and Science. Then, the letter of permission was obtained from administrative bodies of the Misha district administration.

\section{Consent}

The purpose of the study was explained to the study participants to confirm whether they are willing to participate. Finally, written consent was obtained from each study participant before the interview, and confidentiality was secured.

\section{Conflicts of Interest}

The authors declare that they have no conflicts of interest.

\section{Authors' Contributions}

LA was involved in conception, design, analysis, interpretation, and report and manuscript writing. AB, BE, TT, DS, and TS were involved in the design, analysis, interpretation, and report writing. All Authors read and approved the final manuscript.

\section{Acknowledgments}

The authors want to thank Wachemo University for funding this study. The authors want to give their sincere appreciation to data collectors, supervisors, and participants for their willingness to participate in study.

\section{References}

[1] M. Shekar, R. Heaver, and Y.-K. Lee, Repositioning Nutrition as Central to Development: A Strategy for Large Scale Action, World Bank Publications, Herndon, VA, USA, 2006.

[2] D. J. P. Barker, K. M. Godfrey, P. D. Gluckman, J. E. Harding, J. A. Owens, and J. S. Robinson, "Fetal nutrition and cardiovascular disease in adult life," The Lancet, vol. 341, no. 8850, pp. 938-941, 1993.
[3] S. Subarnalata and B. Panda, "A study of nutritional status of pregnant women of some villages in Balasore district, Orissa," Journal of Human Ecology, vol. 20, no. 3, pp. 227-232, 2006.

[4] Federal Democratic Republic of Ethiopia MoH, Health Sector Development Programme IV 2010/11 - 2014/15, Federal Democratic Republic of Ethiopia $\mathrm{MoH}$, Addis Ababa, Ethiopia, 2010.

[5] Central Statistical Agency and ORC Macro, Central Statistical Agency [Ethiopia] and ICF International: Ethiopia Demographic and Health Survey, Central Statistical Agency and ORC Macro, Calverton, MA, USA, 2016.

[6] M. M. Edris, H. Tekle, Y. Fitaw, B. Gelaw, and T. A. D. Engedaw, Maternal Nutrition, Ethiopian Health Center Team, Addis Ababa, Ethiopia, 2005.

[7] A. Abdella, "Maternal mortality trend in Ethiopia," Ethiopian Journal of Health Development, vol. 24, no. 1, 2010.

[8] I. Y. CN. Infant and Young, Child Nutrition Project; Literature Review Prepared for the Message and Materials Development Workshop Produced through Support provided, United States Agency for International Development (USAID), Addis Ababa, Ethiopia, 2011.

[9] Y. M. Demilew, G. D. Alene, and T. Belachew, "Dietary practices and associated factors among pregnant women in West Gojjam Zone, Northwest Ethiopia," BMC Pregnancy and Childbirth, vol. 20, no. 1, p. 18, 2020.

[10] M. S. Alemayehu and E. M. Tesema, "Dietary practice and associated factors among pregnant women in gondar town north west, Ethiopia," International Journal of Nutrition and Food Sciences, vol. 4, no. 6, pp. 707-712, 2015.

[11] A. Nana and T. Zema, "Dietary practices and associated factors during pregnancy in northwestern Ethiopia," BMC Pregnancy and Childbirth, vol. 18, p. 183, 2018.

[12] T. Z. Diddana, "Factors associated with dietary practice and nutritional status of pregnant women in Dessie town, northeastern Ethiopia: a community-based cross-sectional study," BMC Pregnancy and Childbirth, vol. 19, no. 1, p. 517, 2019.

[13] S. Aliwo, M. Fentie, T. Awoke, and Z. Gizaw, "Dietary diversity practice and associated factors among pregnant women in North East Ethiopia," BMC Res Notes, vol. 12, p. 123, 2019.

[14] L. Shehab, "Nutritional awareness of women during pregnancy," Journal of American Science, vol. 8, no. 7, 2012.

[15] E. M. Wahome, W. K. Makau, and W. K. Kiboi, "Predictors of dietary practices and nutritional status among diabetic type II patients in Kiambu County, Kenya," International Journal of Community Medicine And Public Health, vol. 5, no. 7, pp. 2726-2734, 2018.

[16] T. Zelalem, A. Erdaw, and E. Tachbele, "Nutritional knowledge, attitude and practices among pregnant women who attend antenatal care at public hospitals of Addis Ababa, Ethiopia," International Journal of Nursing and Midwifery, vol. 10, no. 7, pp. 81-89, 2018. 